\title{
Psychological distress, associated factors and coping strategies among female student nurses in the Nurses' Training School Galle
}

\author{
YG Ellawela ${ }^{1}$, P Fonseka $^{2}$
}

\begin{abstract}
Objectives

To assess the prevalence, describe selected factors associated with status of psychological distress and coping strategies among female student nurses in the Nurses' Training School (NTS) Galle.

\section{Methods}

A descriptive cross-sectional study was carried out among 525 female student nurses in the NTS Galle in 2009. A self -administered questionnaire (SAQ) identified work and non-work related factors. The validated General Health Questionnaire-30 (GHQ-30) Sinhala version was used for the assessment of the status of psychological distress, with a score of $\geq 6$ confirming psychological distress. Problem-focused and emotion-focused coping strategies for stress were identified using a SAQ. Logistic regression analysis was applied and results were expressed as odds ratios (OR) and $95 \%$ confidence intervals $(95 \% \mathrm{CI})$.
\end{abstract}

\section{Results}

The prevalence of psychological distress among student nurses was $46.6 \%(\mathrm{n}=239)$. Among work related factors, dissatisfaction about the training environment, boredom at work and fear of failure in examinations were significantly associated with psychological distress among them $(\mathrm{p}<0.05)$. Conflicts with colleagues and unavailability of professional counseling service in the NTS were also stressors that significantly affected the psychological distress status $(\mathrm{p}<0.05)$.

Among non-work related factors, a death of a family member or a close person, increasing arguments with family members and missing opportunities to meet loved ones were significantly associated with psychological distress $(\mathrm{p}<0.05)$.

More than $40 \%$ of student nurses seldom practised a problem-focused coping strategy.

\section{Conclusions}

The proportion of female student nurses with psychological distress was high. Programmes to improve life skills, specially coping strategies and provision of professional counseling services are recommended.

\section{Key words:}

Student nurses; Psychological distress; Coping strategies; Sri Lanka

\section{Introduction}

The nursing profession ranks as one of the most respected occupations in the nation. It is a helping profession that provides services for the health and wellbeing of people and is not merely a profession but a social service. Nursing's social policy document (2003) (1) describes nursing as protection, promotion and optimization of health abilities, prevention of illness and injury, alleviation of suffering through diagnosis and treatment of human response and advocacy in the case of individuals, families, communities and population. Although the origin of nursing predates the mid-nineteenth century, the history of professional nursing begins with Florence Nightingale. In 1860, Nightingale set up the first Nurses' Training School at St. Thomas Hospital, London. This became the foundation of most nursing programmes within the western world. By 1887, Nightingale's nurses were working in Australia, Canada, Germany, Sweden, USA, India and Sri Lanka.

In Sri Lanka the first school of nursing was established in Colombo in 1939. The Nursing Training School
(NTS) Galle has a history of being the third NTS in Sri Lanka and was opened in 1956. According to estimations the total nursing workforce in Sri Lanka is 24,988 and the largest health professional group in Sri Lanka (2).

Modern nursing has become both complex and extensive due to new functions and responsibilities added to it throughout the years. Therefore, there is a demand not only for increasing the number of nurses, but for an improvement of the quality of nursing care. Nursing education aims to produce a life long learner who can adapt effectively to changes in both the theory and the practice of nursing and prepare general nurses for employment in the national health care system. The Ministry of Health $(\mathrm{MoH})$ bears the responsibility of producing a sufficient number of effective and efficient nurses to the national health care system. To achieve this goal there are 17 NTSs functioning under the $\mathrm{MoH}$ (Personal communication with Director Nursing Education).

1. Trainee MD Community Medicine, PGIM, Colombo

2. Former Professor of Community Medicine, Faculty of Medical Sciences, University of Sri Jayawardenepura 
A three year general nursing curriculum consists of several theory courses based on medical subjects, practical/clinical training and four week community health training. The medium of instruction in the NTS Galle is mainly in the Sinhala language.

The student nurses, who enter the NTSs, are young women whose problems and needs are similar to others of their age. The new environment of the nursing school and the clinical setup add extra needs and problems to this list (3). Nurses, during the period of training have to work hard for the fulfillment of their career needs. A young nursing student maybe inexperienced and unprepared to face the academic and clinical environment. With the new challenges on her life she may get emotionally tensed and stressed.

A certain amount of stress is needed to stimulate and motivate us to achieve our goals. This beneficial or positive stress is called as "eu stress". A large imbalance between the demand made by the stress causing events and the ability to cope with the situation may result in a negative kind of stress affecting the psychological status of an individual. This condition is described as "psychological distress". It is a state of anxiety, minor depressive illness and transient situational disturbances such as feeling of incompetence in coping (4). Causative factors of stress are multiple and thus avoiding stress is impossible. Factors associated with stress can be categorized into three groups: socio-demographic, individual and occupational (5).

Stress among nursing students is considered as a global issue and the identification of potential stressors among them has received much attention according to the literature (6). Fear of making mistakes in clinical procedures that can cause harm to their patients enhance their stress in these practical circumstances. The General Health Questionnaire (GHQ) developed by Goldberg in 1969 has been extensively used to assess psychological distress (7),(8). The GHQ-30 has been validated in Sri Lanka (9).

Although students cannot avoid these stressors, it is important to acquire the ability to adjust to their demands. Behaviours and thoughts that a person uses to handle stress are called coping strategies (10).

Coping efforts may be focused on managing or altering a problem causing distress (problem-focused) or regulating unpleasant emotions (emotion-focused) that are created due to the problem. The latter can be further subdivided into cognitive and behavioural. There may be harmless situations. Practically all problems cannot be solved. Often we practice combination of both problem- focused and emotion-focused strategies (11). Awareness of such coping strategies to be used by the nursing students is important as adoption to positive coping methods is the easiest and simplest way for coping with stress.

\section{Methodology}

A descriptive cross-sectional study was carried out among, $2^{\text {nd }}$ and $3^{\text {rd }}$ year female student nurses in the NTS Galle in 2009, as there were no $1^{\text {st }}$ year nursing student group. All 525 female student nurses at the NTS Galle belonged to $2^{\text {nd }}$ and $3^{\text {rd }}$ years, was the study population. The calculated sample size was 422. Since it was feasible, all eligible subjects were included without sampling. Three study instruments were used to collect the required information. A self-administered questionnaire was used to collect demographic and socio-economic characteristics of student nurses and work and nonwork related factors. The psychological distress among nurses was assessed using the General Health Questionnaire-30 (GHQ-30). A score of $\geq 6$ was considered as having psychological distress. Coping strategies used by the nurses were collected using another self administered questionnaire. Frequency of practicing coping strategies, were analyzed according to problem-focused and emotionfocused strategies. Logistic regression analysis was applied to assess the significance of relationships.

\section{Results}

Total response rate was $97.7 \%(n=513)$. The frequency distribution of the female student nurses according to the year of study by age, ethnicity and religion is shown in Table 1. 
Table 1 Frequency distribution of female student nurses by year of study and age, ethnicity and religion

\begin{tabular}{|c|c|c|c|c|c|c|}
\hline \multirow{3}{*}{ Characteristic } & \multicolumn{4}{|c|}{ Year of study } & \multicolumn{2}{|c|}{ Total } \\
\hline & \multicolumn{2}{|c|}{$3^{\text {rd }}$ year } & \multicolumn{2}{|c|}{$2^{\text {nd }}$ year } & \multirow[b]{2}{*}{ No. } & \multirow[b]{2}{*}{$\%$} \\
\hline & No. & $\%$ & No. & $\%$ & & \\
\hline \multicolumn{7}{|l|}{ Age in com- } \\
\hline \multicolumn{7}{|l|}{ plete years } \\
\hline $22-24$ & 97 & 46,6 & 222 & 72.8 & 319 & 62.2 \\
\hline $25-27$ & 109 & 52.4 & 68 & 22.3 & 177 & 34.5 \\
\hline$\geq 28$ & 2 & 1.0 & 15 & 4.9 & 17 & 3.3 \\
\hline Total & 208 & 100 & 305 & 100 & 513 & 100 \\
\hline Mean \pm SD & \multicolumn{2}{|c|}{ 24. $7 \pm 1.1$ years } & \multicolumn{2}{|c|}{$24.1 \pm 1.5 \quad$ years } & \multicolumn{2}{|c|}{$24.3 \pm 1.4$ years } \\
\hline \multicolumn{7}{|l|}{ Ethnicity } \\
\hline Sinhalese & 207 & 99.5 & 304 & 99.7 & 511 & 99.6 \\
\hline Tamil & 1 & 0.5 & 1 & 0.3 & 2 & 0.4 \\
\hline Total & 208 & 100 & 305 & 100 & 513 & 100 \\
\hline \multicolumn{7}{|l|}{ Religion } \\
\hline Buddhist & 207 & 99.5 & 300 & 98.4 & 507 & 98.8 \\
\hline Christian & 1 & 0.5 & 5 & 1.6 & 6 & 1.2 \\
\hline Total & 208 & 100.0 & 305 & 100.0 & 513 & 100.0 \\
\hline
\end{tabular}

The proportion of female student nurses with psychological distress was 46.6\% (95\%CI 42.3-50.9) (Table 2).

Table 2 Frequency distribution of female student nurses according to status of psychological distress

\begin{tabular}{llll}
\hline Status of psychological distress & No. & $\mathbf{\%}$ & *95\% CI \\
\hline Distressed & 239 & 46.6 & $42.3-50.9$ \\
Not distressed & 274 & 53.4 & \\
\hline Total & $\mathbf{5 1 3}$ & $\mathbf{1 0 0 . 0}$ & \\
\hline *95\% Confidence Interval & & &
\end{tabular}

When the work related factors were presented in decreasing order of frequency, it can be observed that more than $50 \%$ female student nurses were affected by six factors. Among those factors the majority $(85 \%, \mathrm{n}=436)$ of the female student nurses were affected by work over load followed by dissatisfaction of work $(63.5 \%, \mathrm{n}=326)$, boredom at work $(62 \%, \mathrm{n}=318)$ and fear of failure in exams $(59 \%, \mathrm{n}=304)$ (Figure 1$)$. 
Figure 1 Frequency distributions of participants in the study sample affected by each work related factor during past four weeks

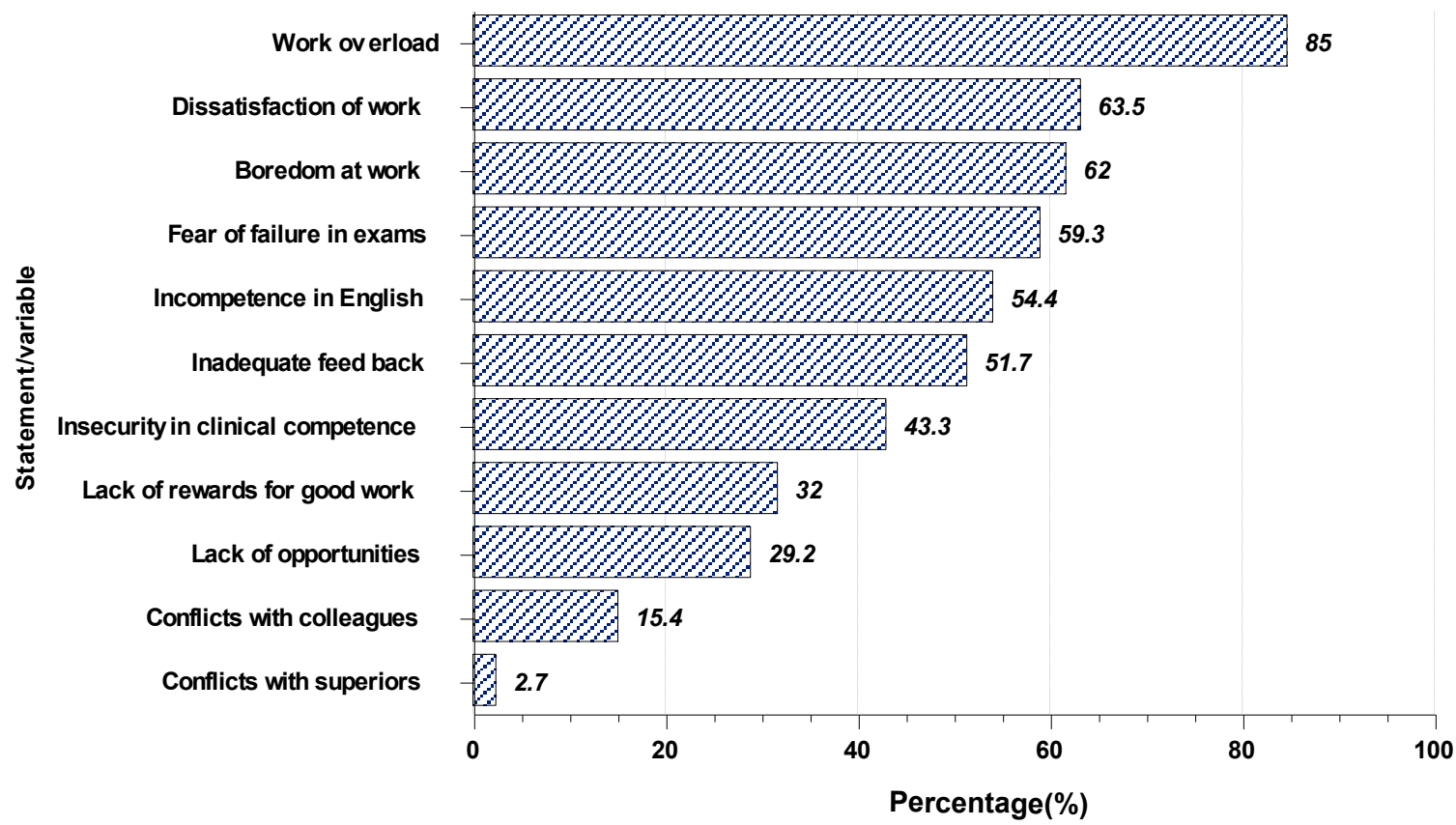

Some of the variables that were significant in the univariate analysis were not found to be significant after removing the confounding effects by the logistic regression model.

The work related and non-work related factors significantly associated with psychological distress are presented in Table 3 .

Table 3 Factors significantly associated with psychological distress

95\% CI of OR

Variable

Coefficient Std. p-value Odds Ratio Lower Upper

Work related factors

Dissatisfaction about the train-

ing environment

$\begin{array}{llllll}-0.62 & 0.23 & 0.01 & 0.54 & 0.34 & 0.83\end{array}$

Boredom at work

$-0.68<0.21<0.001$

0.50

0.33

0.77

Fear of failure in examinations

0.59

0.21

0.01

1.80

1.18

2.74

Conflicts with colleagues

0.71

$0.29 \quad 0.02$

2.03

1.14

3.59

\section{Non work related factors}

Increasing arguments with fami-

ly members

$\begin{array}{llllll}1.00 & 0.30 & <0.001 & 2.72 & 1.50 & 4.93\end{array}$

Missing opportunities to meet

loved ones

$\begin{array}{llllll}0.50 & 0.20 & 0.01 & 1.65 & 1.12 & 2.44\end{array}$

Death of a family member or a

close person

0.47

0.23

0.04

1.60

1.02

2.49 
Four of the work related factors and all non-work related factors considered except an illness or a major injury of female student nurses and financial problems in the family, were significantly associated with psychological distress. Availability of a counselor in problematic situations was analyzed separately as it was not directly associated with the training itself. Of the total student nurses, $46 \%(\mathrm{n}=236)$ had no access to a counselor, when they encountered problems.

The association between the status of psychological distress and presence of a person to get counseling at the NTS was statistically significant $(\mathrm{p}<0.001)$.

Frequency distribution of practising two main coping strategies: problem-focused and emotion-focused (harmless and harmful) are presented in Table 4 and 5.

More than $40 \%$ of student nurses seldom practised each of the problem-focused coping strategies.

The majority $(52.6 \%, \mathrm{n}=270)$ of the female student nurses sought comfort in religious or spiritual beliefs.

Table 4 Frequency distribution of female student nurses according to frequency of practising problem-focused stress coping strategies

\begin{tabular}{|c|c|c|c|c|c|c|c|c|}
\hline \multirow{3}{*}{ Situation/ coping strategy } & \multicolumn{6}{|c|}{ Frequency } & \multirow{2}{*}{\multicolumn{2}{|c|}{ Total }} \\
\hline & \multicolumn{2}{|c|}{ Never } & \multicolumn{2}{|c|}{ Seldom } & \multicolumn{2}{|c|}{ Frequently } & & \\
\hline & No. & $\%$ & No. & $\%$ & No. & $\%$ & No. & $\%$ \\
\hline $\begin{array}{l}\text { I looked for something in what } \\
\text { has happened and tried to make it } \\
\text { seem more positive }\end{array}$ & 17 & 3.3 & 290 & 56.5 & 206 & 40.2 & 513 & 100.0 \\
\hline $\begin{array}{l}\text { I thought hard about what steps } \\
\text { to take and tried to come up with } \\
\text { an appropriate strategy }\end{array}$ & 13 & 2.5 & 208 & 40.5 & 292 & 56.9 & 513 & 100.0 \\
\hline $\begin{array}{l}\text { I tried to get advice from relevant } \\
\text { people and worked accordingly }\end{array}$ & 137 & 26.7 & 264 & 51.5 & 112 & 21.8 & 513 & 100.0 \\
\hline $\begin{array}{l}\text { I put aside other activities in or- } \\
\text { der to concentrate on this }\end{array}$ & 209 & 40.7 & 269 & 52.4 & 35 & 6.8 & 513 & 100.0 \\
\hline $\begin{array}{l}\text { I forced my self not to make mat- } \\
\text { ters worse by acting too soon and } \\
\text { waited for the right time to do }\end{array}$ & 30 & 5.8 & 232 & 45.2 & 251 & 48.9 & 513 & 100.0 \\
\hline
\end{tabular}


Table 5 Frequency distribution of female student nurses according to frequency of practicing each category emotion-focused coping strategies

\begin{tabular}{|c|c|c|c|c|c|c|c|c|}
\hline \multirow{3}{*}{ Situation/strategy } & \multicolumn{4}{|c|}{ Frequency } & & & \multirow{2}{*}{\multicolumn{2}{|c|}{ Total }} \\
\hline & \multicolumn{2}{|c|}{ Never } & \multicolumn{2}{|c|}{ Seldom } & \multicolumn{2}{|c|}{ Frequently } & & \\
\hline & No. & $\%$ & No. & $\%$ & No. & $\%$ & No. & $\%$ \\
\hline \multicolumn{9}{|l|}{ Emotional harmless } \\
\hline $\begin{array}{l}\text { I tried to reduce stress by physi- } \\
\text { cal exercise }\end{array}$ & 342 & 66.7 & 133 & 25.9 & 38 & 7.4 & 513 & 100.0 \\
\hline $\begin{array}{l}\text { I tried to find comfort in } \\
\text { my religion or spiritual } \\
\text { beliefs }\end{array}$ & 41 & 8.0 & 202 & 39.4 & 270 & 52.6 & 513 & 100.0 \\
\hline $\begin{array}{l}\text { I tried to reduce stress by listen- } \\
\text { ing to music }\end{array}$ & 40 & 7.8 & 286 & 55.8 & 187 & 36.5 & 513 & 100.0 \\
\hline $\begin{array}{l}\text { I tried to get emotional } \\
\text { support and comfort from friends/ } \\
\text { colleagues }\end{array}$ & 65 & 12.7 & 270 & 52.6 & 178 & 34.7 & 513 & 100.0 \\
\hline \multicolumn{9}{|l|}{ Emotional harmful } \\
\hline $\begin{array}{l}\text { I took drugs such as } \\
\text { Diazepam }\end{array}$ & 502 & 97.9 & 7 & 1.4 & 4 & 0.8 & 513 & 100.0 \\
\hline I kept feeling to myself & 236 & 46.0 & 212 & 41.3 & 65 & 12.7 & 513 & 100.0 \\
\hline I starved & 357 & 69.6 & 145 & 28.3 & 11 & 2.1 & 513 & 100.0 \\
\hline I tried to venting anger on others & 320 & 62.4 & 180 & 35.1 & 13 & 2.5 & 513 & 100.0 \\
\hline \multicolumn{9}{|l|}{ Cognitive } \\
\hline $\begin{array}{l}\text { Reappraised the situation to make } \\
\text { it less stressful }\end{array}$ & 106 & 20.7 & 321 & 62.6 & 86 & 16.8 & 513 & 100.0 \\
\hline $\begin{array}{l}\text { I tried to think that it was } \\
\text { not a serious concern }\end{array}$ & 46 & 9.0 & 292 & 56.9 & 175 & 34.1 & 513 & 100.0 \\
\hline
\end{tabular}

\section{Discussion}

This study was carried out among female nursing students in the NTS Galle, with the aim of describing work and non-work related factors among female nursing students, assess the status of psychological distress, and to describe; the factors associated with psychological distress and the coping strategies adopted by them to overcome stress.

The respondent rate in the study was $97.3 \%$, which is much higher than $74.6 \%$ reported in the study among university students (12). Three study instruments were used: 1) a self administered questionnaire (SAQ) collected demographic, socio-economic characteristics, work and non-work related factors, 2) assessment of psychological distress using the already validated General Health Questionnaire-30 (GHQ-30) Sinhala version and 3) a SAQ to gather information on problem-focused and emotion-focused coping strategies for stress.

The mean age of the 513 female student nurses, who participated in the study, was $24 \pm 1.4$ years. This study revealed that $46.6 \%$ female student nurses were psychologically distressed. In a study done among undergraduates in five universities in Sri Lanka, $39.8 \%$ were found to be psychologically distressed (12). A study done by Dassanayaka revealed that the prevalence of psychological distress among postgraduate trainees in selected medical 
specialties was $39.9 \%$ (13). Thus the present study shows a higher prevalence of psychological distress among student nurses compared to university undergraduates and medical postgraduate trainees. Since no studies have been done previously on psychological distress among Sri Lankan nursing students, a direct comparison between the same professional category was not possible.

Though a majority of female student nurses were affected by work overload (85\%), a significant association with psychological distress was not found. Dissatisfaction about the training environment, boredom at work and fear of failure in examinations were identified as main stressors during the training that were significantly associated with psychological distress among them $(\mathrm{p}<0.05)$.

Conflict situations with colleagues and unavailability of professional counseling service in the NTS were associated with psychological distress status significantly $(\mathrm{p}<0.05)$.

Among non-work related factors, a death of a family member or a close person, increasing arguments with family members and missing opportunities to meet loved ones were significantly associated with psychological distress $(p<0.05)$. More than $40 \%$ of student nurses had seldom practised each of problem-focused coping strategies. The majority of the female student nurses sought comfort in religion or spiritual beliefs, while harmful coping strategies were practised by a smaller proportion of them.

\section{Conclusions and recommendations}

The proportion of female student nurses with psychological distress was high. The majority of work and non -work related factors considered were associated with psychological distress.

The infrequent practice of each problem focused coping strategy by female student nurses indicates overall decrease of adaptation to healthy ways of coping. The relatively less proportion of female student nurses $(21.8 \%)$ who tried to get advice from others indirectly represent the unavailability of proper counseling services. It is worthwhile to mention that approximately $57 \%$ of female student nurses had tried to come up with an appropriate strategy when they had encountered a problem.

Improving the physical as well as the psychological training environment of the NTS by advocacy and training of tutors is recommended in order to reduce psychological distress caused by unfavorable conditions in the training environment. It is important to establish a professional counseling service in the NTS with an adequate number of well trained counselors, to meet the counseling needs of the student nurses. Including life skills development into the nursing training, curriculum with greater emphasis on interpersonal relationships will reduce psychological stress and improve coping skills of the trainee nurses. Periodic stress management workshops will further reduce psychological stress among student nurses and enhance their coping abilities to deal with stressful situations.

\section{References}

1. American Nurses Association. Nursing's social policy statement. 2003; 2nd ed.

2. Medical Statistics Unit. Annual Health Statistics Sri Lanka- 2006. 2th ed.Department of Health. Ministry of Healthcare and Nutrition. Sri Lanka; 2009.

3. Heidgerken LE. Teaching and Learning in schools of Nursing; Principles and methods. $3^{\text {rd }}$ ed. Philadeiphia: JB. Lippincot; 1965.

4. Selye H. Stress and conflict. In: Garrison M. ed. Introduction to Psychology. New York: Ohio mission Hills; 1974.

5. Cox T, Griffiths A, Cox S. Work related stress in nursing: working paper 4. 1996. International Labour Office Geneva. Available from http://www.ilo.org [Accessed 26 ${ }^{\text {th }}$ April 2009]

6. Beck DL, Srivastava R. Perceived level and sources of stress in baccalaureate nursing students. Journal of Nursing Education. 1991; 30 (3): 127-133.

7. Goldberg DP, Willams P. A user's Guide to General Health Questionnaire. NFER- Nelson Windsor; 1998.

8. Jones MC, Jhonston DW. Distress, stress and coping in First Year Student Nurses. Journal of Advanced Nursing. 1997; 26 (4): 475-484.

9. Sumathipala A. A study of psychiatric disturbances in patients with multiple complains and repeated consultations [Thesis]. Postgraduate Institute of Medicine: University of Colombo; 1990.

10. Garrison M. Introduction to Psychology. New York: Ohio Mission Hills; 1992.

11. Atkinson RL, Atkinson RC, Smith EE, Bem DJ. An introduction to psychology. $10^{\text {th }} \mathrm{ed}$. 1990.

12. Kuruppuarachchi KALA, Kuruppuarachchi KAJM, Wijerathne S, Williams SS. 2002. Psychological distress among students from five universities in Sri Lanka. Ceylon Medical Journal. 2002; 47(1):13-5.

13. Dassanayake GK. Factors associated with stress, coping strategies and stress among Postgraduate trainees of selected medical specialities [Dissertation]. Postgraduate Institute of Medicine: University of Colombo; 2003. 